\title{
Population Evacuation Need Assessment in Cyclone Affected Barguna District
}

\author{
Umma Tamima*
}

\begin{abstract}
Spatial difference in geophysical risk and social vulnerability presents challenges to emergency planners to develop an effective evacuation strategy for cyclone zones. This study examines spatial variability in evacuation assistance needs during cyclone hazard in Barguna district. For this, composite vulnerability map of unions in Barguna district is developed based on the community demographics, resources, structures and geophysical risk indicators. Four evacuation dimensions are analyzed based on population traits and building structures index, differential access to resources index, special evacuation needs index and a combination of three dimensions. Results indicate that relative majority of the unions are characterized by high evacuation assistance need and similar scenario exists in the spatial distribution of geophysical risk and socio-economic vulnerability. Nevertheless, spatial disparity of socioeconomic vulnerability is also observed among the unions within the geophysical risk zone. The coastal unions of Barguna districts are identified as the geophysical risk zone of which Raihanpur, Bardarkhali, Keorabunia, Burir Char, Amtali, Haldia, Arpagashia, Barguna, Dhalua, Kakchira, Nachnapara, Kantaltali, Char Duanti, Kalmegha, Patharghata, Barabagi, Karaibaria, Pancha Karalia, Naltona, and Baliatali unions are within the high geophysical risk zone. Furthermore, depending on the indices it is revealed that 72.26 percent people are living within the geophysical risk zone, while 17.72 percent and 47.42 percent people are living within the high and medium socio-economic vulnerable regions respectively. Thus this study finds out that about 65.14 percent people of Barguna district require evacuation assistance needs.
\end{abstract}

\section{Introduction}

The coastal zone in Bangladesh reflects a rural setting and contains a significant portion of population of Bangladesh. In 2001, a total of 35.1 (23 percent of the total population of Bangladesh) million people live in the coastal zone in Bangladesh, which was only 8.1 million a century earlier (WARPO, 2004). The coastal districts of Bangladesh are mainly susceptible to cyclones and storm surge and subjected to severe damages frequently. For instance, the extent of damage caused by the last catastrophic cyclone SIDR, which swept through Bangladesh coast on 15 November 2007, was about \$450 million. The entire Patuakhali, Barguna and Jhalokati districts were hit hard by the storm surge of over 5 meters $(16 \mathrm{ft})$. In Barguna district, 1335 people were died (44.5 percent of total casualties), $1119.89 \mathrm{sq} . \mathrm{km}$. area was annihilated (61.15 percent of total area), 60-70 percent of crop was lost and 95,412 houses were fully and partially damaged (36.89 percent of total) (NIRAPAD, 2007). Along this, Barguna was also affected by severe cyclones during 1935, 1965, and 1970. Thus, developing an effective strategy for disaster management of Barguna district based on the geophysical risk and vulnerability presents challenges to emergency planners.

Generally speaking, vulnerability to environmental hazards means the potential for loss. Since losses vary geographically, over time, and among different social groups, vulnerability also varies over time and space. Vulnerability has many different connotations depending on the orientation and perspective of researches (Dow, 1992; Cutter, 1996, 2001; Blaikie et al., 1994; Clark et al., 1998; Cutter, 1996; Hewitt, 1997; Kasperson et al., 1995; Montz, 1994; Susman et al., 1983;

Lecturer, Department of Urban and Regional Planning, Bangladesh University of Engineering and Technology, Dhaka. E-mail: umma_tamima@urp.buet.ac.bd 
Tobin and Montz, 1997; and UNISDR, 2001), but few clear measures of social vulnerability have been established. However, this article utilizes similar parameters of the hazards-of-place model of vulnerability to examine the components of social vulnerability (Cutter et al., 2003).

The objectives of this paper are to assess population evacuation needs during the period of cyclone based on geophysical risk and socio-economic vulnerability of different unions of Barguna district and to prepare a composite vulnerability map based on the community demographics and geophysical risk during the catastrophic cyclone SIDR 2007.

\section{Study area}

Barguna District, having an area of $1831.31 \mathrm{sq} \mathrm{km}$ and population of 179968 , is bounded by Payra River, Bishkhali River and Baleshwar River (BBS, 2006). Barguna is divided into 5 upazilas (Amtali, Betagi, Bamna, Barguna Sadar and Patharghata), 38 unions, 238 mouzas and 560 villages (Banglapedia, 2006). Barguna district was chosen as the study area, because it is always affected by storm surge, coastal flooding, and other hazards associated with cyclone. The study area has been directly threatened numerous times by cyclone and tropical storms, although few have made landfall in this district. The historic dataset (1877-2003) of land falling storm track in Bangladesh, developed by Islam (2008) applying Global Tropical Cyclone Climatic Atlas (GTCCA) revealed that thirty-five depressions, storms and cyclones hit Barguna district during the last 130 years (Table 1). Among them, seven storms were significant due to their magnitude. The most severe events include SIDR (2007) and cyclone in 1970.

Table 1: List of historic storm track in Barguna District (1877-2007)

\begin{tabular}{|l|l|l|l|l|l|}
\hline \multicolumn{1}{|c|}{ Year } & \multicolumn{1}{|c|}{ Cyclone type } & \multicolumn{1}{|c|}{ Year } & \multicolumn{1}{c|}{ Cyclone type } & \multicolumn{1}{c|}{ Year } & \multicolumn{1}{|c|}{ Cyclone type } \\
\hline 1887 & $\begin{array}{l}\text { Tropical Depression } \\
\left(\text { TD }^{1}\right)\end{array}$ & 1928 & TD & 1961 & TS (60 Knots) \\
\hline 1888 & Tropical Storm $\left(\mathrm{TS}^{23}\right)$ & 1929 & TD & 1964 & TD \\
\hline 1890 June & TD & 1932 & TD & 1965 & $(34-47$ Knots) \\
\hline 1890 Oct & TS & 1937 & TS & 1967 & TS \\
\hline 1895 & $34-47$ Knots & 1938 May & TD & 1970 & 130 Knots \\
\hline 1913 & TD & 1938 August & TD & 1974 & 75 Knots \\
\hline 1916 & TS & 1941 June & TD & 1977 & TS (60 Knots) \\
\hline 1917 & TD & 1941 July & TD & 1988 & TS (35 Knots) \\
\hline 1919 & TD & 1941 August & TS & 1988 & 110 Knots \\
\hline 1920 & TD & 1950 & TD & 1997 & 65 Knots \\
\hline 1923 & TD & 1958 & TD & 2007 & 133 Knots \\
\hline 1924 & TD & 1959 & TD & & \\
\hline
\end{tabular}

Source: Islam, 2008 and BMD

\footnotetext{
${ }^{1}$ Tropical Depression (TD): a tropical cyclone with winds equal to or less than 27 knots.

3 Tropical Storm (TS): a tropical cyclone with winds stronger than 27 knots but less than 66 knots.
} 


\section{Methodology}

\section{Modelling Cyclone Induced Coastal Flooding to Determine Geophysical Risk of Barguna District}

Cyclones are synoptic scale events and influence the environment over a large area in the scale of over $1000 \mathrm{~km}$ (Maniruzzaman, 1997). Geophysical risk of cyclone mostly depends on two parameters i.e. wind speed and storm surge. 'Multipurpose Cyclone Shelter Program (MCSP)' of Bangladesh University of Engineering and Technology and Bangladesh Institute of Development Studies and 'National Survey on Current Status of Shelters and Developing and Operational CYSMIS' of Center for Environmental and Geographic Information Service (CEGIS) have delineated coastal districts of Bangladesh into two geophysical risk zones e.g. high-risk and risk zones. According to the study of MCSP (1993), Risk Zone (RZ) extends from the coastline (coast or riverbank) to an inland limit up to which surge water can reach and the High Risk Zone (HRZ) extends from the coastline up to a limit, where the storm surge can inundate more than one-meter height of land (BUET and BIDS, 1993). The above two categories of risk zones in Barguna district were considered for the evacuation planning.

Moreover, in order to predict the storm surge effect of cyclone, the Bay of Bengal model was used. The available Bay of Bengal model for surge simulation is based on MIKE21 modelling systems, which is a general numerical modelling system for the simulation of water levels and flows in estuaries, bays and coastal areas. The model complex comprises of two modules: a twodimensional depth integrated hydrodynamic model (MIKE 21 NHD) and a cyclone model (CYWIND). The tidal calibrated and validated hydrodynamic model with input from cyclone model was used to calibrate the surge level using the wind friction factor as calibration parameter only. The database required for the cyclone model was collected from the Bangladesh Meteorological Department (BMD).

Furthermore, a reconnaissance survey was conducted to collect information on storm surge height (recall of the memory of the local people) in different unions of Barguna district during SIDR 2007. The surge depth data were identified by comparing with the permanent objects of the locality e.g. building, trees etc. The maximum distance of surge line from the coast i.e. the maximum distance up to which surge water reached was also determined through the discussion with local people, which was further cross-checked with the model study.

\section{Measuring Social Vulnerability}

The literature on assessment of social vulnerability has identified several characteristics those contribute to differential ability for coping with and recovering from natural hazards. Following the literature on vulnerability analysis, this study focuses on three specific characteristics of the social vulnerability (Table 2 ):

Census data (BBS, 2006) of above-mentioned characteristics were used to assess the evacuation needs. Jurisdiction boundary of Union Parishad is the analytical unit chosen for this study, because it is the smallest local government unit. As all the characteristics of socio-economic vulnerability are not exerting the equal weight, a weighted system is developed based on expert opinion and literature review. Although hazardousness and vulnerability vary at smaller geographic scales and even at the household level (Clark et al. 1998), the Union is a useful and practical unit for advising local officials on the allocation of resources.

This study has also applied the methodology adopted by Chakraborty and others (2005) by formulating an index to measure the social vulnerability of the population for evacuation assessment needs at the union level. However, the methodology used to compute the 'socioeconomic vulnerability for evacuation assistance index (SEVEAI)' in the study area can be summarized as follows:

Step 1: Weights in the scale of 100 were assigned to each variables based on the local and expert opinions. 
Table 2: Variables used to determine social vulnerability

\begin{tabular}{|c|l|l|l|}
\hline \multicolumn{2}{|c|}{$\begin{array}{l}\text { Characteristics } \\
\text { (Weighted) }\end{array}$} & \multicolumn{1}{|c|}{ Variables (Weighted) } & Data Source \\
\hline \multirow{2}{*}{ Geo-physical risk } & 1. High risk area & BUET-BIDS* (1993) \\
and CEGIS (2004)
\end{tabular}

* Multipurpose Cyclone Shelter Program (MCSP)' of Bangladesh University of Engineering and Technology and Bangladesh Institute of Development Studies (1993) and 'National Survey on Current Status of Shelters and Developing and Operational (CYSMIS)' of Center for Environmental and Geographic Information Service (CEGIS) (2004)

** GIS section, Local Government Engineering Department

Step 2: For each variable $i$, ratio of the variable in each union to the total number of that variable in the district $R$ was determined. In case of 'Direct Access to Resources', deprivation of resource in each union was first determined.

Step 3: Standardized socio-economic vulnerability for evacuation index SVEAI for variable $i$ was computed using the maximum ratio value $R$ max. SVEAIi $=\mathrm{Ri} / \mathrm{Rmax}$

Step 4: To combine multiple variables in the assessment of socio-economic vulnerability, weighted mean of the vulnerability indices was calculated by dividing the sum of weighted index values of all variables by the weight of variables $n$ considered.

$$
\mathrm{SVEAI}=\sum w_{i} * S V E A I_{i} / n
$$

The values of SVEAI range from 0 to 1 . Higher scores for this index indicate greater vulnerability for the unions. Later on, four alternative approaches were derived for calculating socio-economic vulnerability and for examining the spatial distribution of each approach within the study area. Each approach represents a combination of socio-economic variables (Table 1). 
- Approach 1: Population and structure (five variables),

- Approach 2: Differential access to resources (eight variables),

- Approach 3: Special evacuation needs (three variables), and

- Approach 4: All three characteristics (16 variables).

\section{Determination of Geophysical Risk Areas}

The main attributes contributing to disastrous surges in the Bay of Bengal, especially in Bangladesh are (a) shallow and wide continental shelf, (b) convergence of the Bay, (c) high astronomical tides (d) thickly populated low lying island and (f) complex coastline and number of inlets including one of the worlds largest river system Ganga-Brahmaputra-Meghna. Figure 1 shows the high-risk area, demarcated in red line in the legend and risk zone (green line) in Barguna district, which is defined by the BUET-BIDS study based on the model study. Therefore all the unions that fall under this line are vulnerable to coastal flooding.

Moreover, the Bay of Bengal model had been calibrated and validated by Institute for Water modeling (IWM). In this study, the model was calibrated for the predicted cyclone for the upcoming 50 years having the wind speed of $261 \mathrm{~km} / \mathrm{hr}^{4}$. The four extraction points of three main rivers in Barguna district (Fig.2) were selected in this model because these rivers caused significant destruction of lives and properties by overtopping and demolishing the embankment in SIDR 2007.

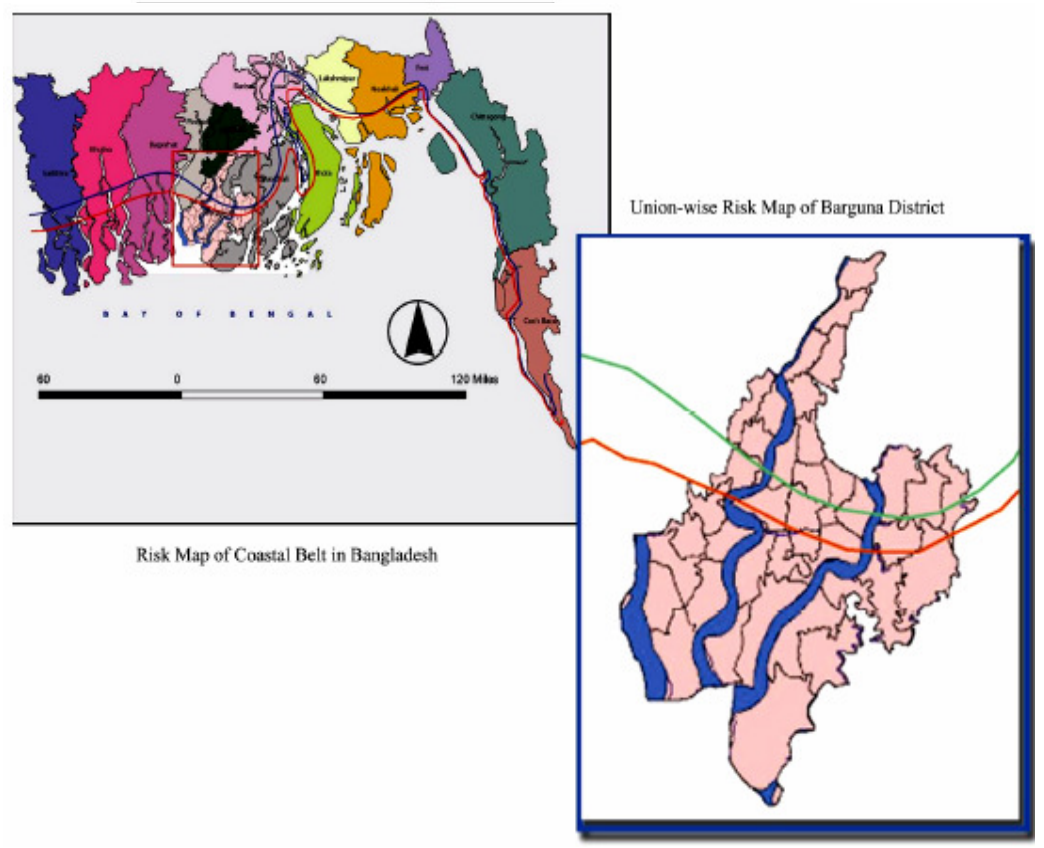

Fig 1: High risk area and risk zone

The extraction points are Point $+\mathrm{t} 3$ at Haringhata River, Point $+\mathrm{t} 2$ at Bishkali River, Point $+\mathrm{t} 1$ at Burirshawr River and Point $+\mathrm{t} 4$ at the confluences of the three rivers. The surge level of the points is compared with the previous cyclone of Barguna district during 1970 and 2007.

\footnotetext{
${ }^{4}$ The wind speed of cyclone during the coming 50 years was predicted by BUET-BIDS study in 1993.
} 


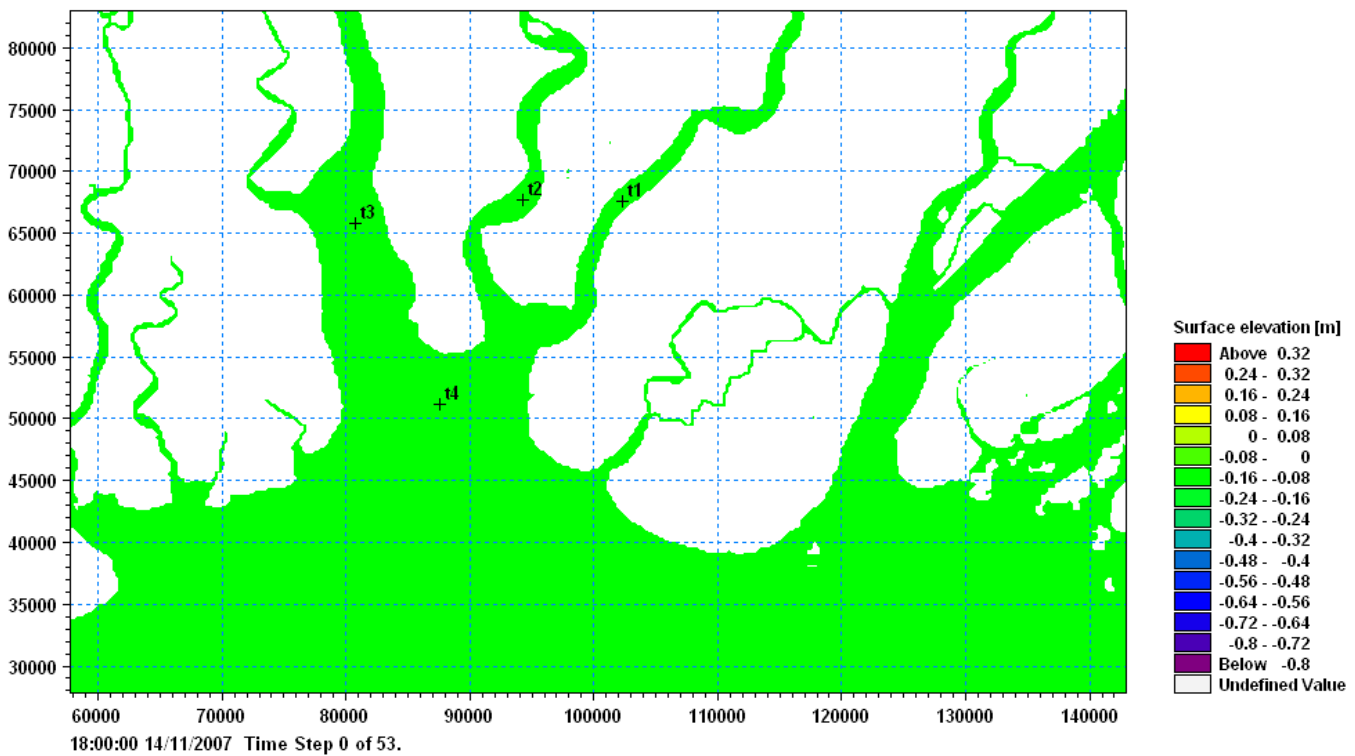

Fig. 2: Extraction point for storm surge in the outlets of Barguna district

The results of Bay of Bengal model show that storm surge level and surge induced coastal flooding reached from the outfall of Baleshwar River up to $50 \mathrm{~km}$ upstream at Morelganj with high surge level, the storm surge level at Patharghata is in the range of 5.5 to $6 \mathrm{~m}$ PWD for the cyclone SIDR (Figure 3). The model study for the predicted cyclone shows that it will be within the range of $6.5 \mathrm{~m}$ to $7.0 \mathrm{~m}$ for the predicted wind speed of $261 \mathrm{~km} / \mathrm{hr}$ (Figure 4 ).

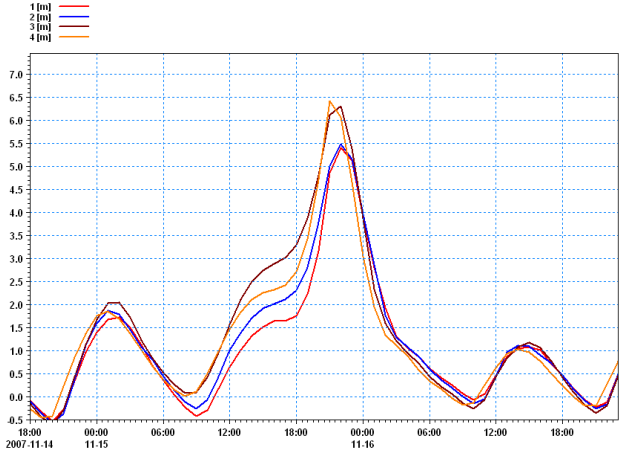

Fig. 3: Surge level at the four points for the cyclone 2007.

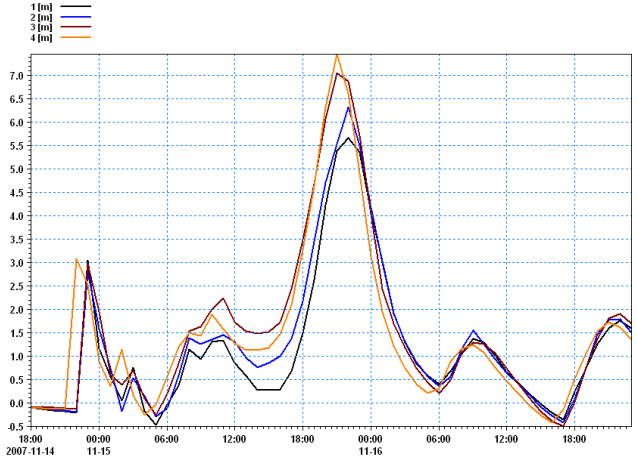

Fig. 4: Time series surge level at the four points for the predicted cyclone with $261-\mathrm{km} / \mathrm{hr}$-wind speed.

The model study of Institute for Water Modeling reveals that surge level exceeds PWD polder embankments (5m height), and surge level does not exceed the sea-facing embankment, which was paradoxical to the field data during 2008 (Table 3 and 4). The field data revealed that except two upazilas in Barguna district, the rest of the three upazilas were submerged by storm surge due to the overtopping of embankment. It is important to note that the height of the embankment is $5 \mathrm{~m}$ along the three upazilas e.g. Patharghata, Amtali and Barguna Sadar. 
Table 3: Fully inundated unions of Barguna district by storm surge during SIDR 2007

\begin{tabular}{|c|c|c|c|c|c|c|c|}
\hline \multirow[b]{2}{*}{ Upazila } & \multicolumn{3}{|c|}{ Full inundated unions } & \multirow[b]{2}{*}{ Upazila } & \multicolumn{3}{|c|}{ Full inundated unions } \\
\hline & Union & $\begin{array}{l}\text { Distance of the } \\
\text { furthest boundary } \\
\text { from the coast } \\
(\mathrm{km})\end{array}$ & $\begin{array}{c}\text { Approximate } \\
\text { surge depth (m) }\end{array}$ & & Union & $\begin{array}{l}\text { Distance of the } \\
\text { furthest boundary } \\
\text { from the coast }(\mathrm{km})\end{array}$ & $\begin{array}{l}\text { Approximate } \\
\text { surge depth } \\
\text { (m) }\end{array}$ \\
\hline \multirow[t]{11}{*}{ Amtali } & Paurashava & 11 & 3.66 & \multirow{8}{*}{$\begin{array}{l}\text { Barguna } \\
\text { Sadar }\end{array}$} & Ayla Patakata & 43.79 & 2.13 \\
\hline & Amtali & 11 & 3.66 & & Badarkhali & 26.62 & 3.66 \\
\hline & Arpangashia & 35 & 3.66 & & Burir Char & 36.35 & 6.71 \\
\hline & Atharagashia & 60 & 2.13 & & Dhalua & 20.77 & 3.05 \\
\hline & Barabagi & 17.66 & 6.71 & & Gaurichanna & 14.21 & 2.13 \\
\hline & Chowra & 37.41 & 6.10 & & Keorabunia & 35.46 & 2.13 \\
\hline & Gulisakhali & 46.92 & 6.10 & & M. Baliatali & 30.07 & 7.62 \\
\hline & Haldia & 36.62 & 2.44 & & Naltona & 14.08 & 7.62 \\
\hline & Karaibaria & 23.81 & 2.44 & \multirow{6}{*}{$\begin{array}{l}\text { Patharghat } \\
\text { a }\end{array}$} & Paurashava & 13.32 & 6.10 \\
\hline & Kukua & 44.10 & 3.05 & & Char Duanti & 20.88 & 6.71 \\
\hline & Pancha Koralia & 29.81 & 7.62 & & Kakchira & 22.67 & 8.54 \\
\hline \multirow{3}{*}{$\begin{array}{l}\text { Pathargh } \\
\text { ata }\end{array}$} & Nachna Para & 25.85 & 4.57 & & Kalmegha & 16.26 & 9.15 \\
\hline & Patharghata & 13.32 & 9.15 & & Kanthaltali & 24.80 & 6.10 \\
\hline & Raihanpur & 29.71 & 4.57 & & & & \\
\hline
\end{tabular}

Source: Field survey, 2008

Table 4: Partially inundated unions of Barguna district by storm surge during SIDR 2007

\begin{tabular}{|c|c|c|c|}
\hline \multicolumn{4}{|c|}{ Partially inundated Unions } \\
\hline Upazila & Union & $\begin{array}{l}\text { Distance of the furthest boundary } \\
\text { from the coast }(\mathrm{km})\end{array}$ & $\begin{array}{l}\text { Approximate surge } \\
\text { depth }(\mathrm{m})\end{array}$ \\
\hline \multirow[t]{8}{*}{ Betagi } & Paurashava & 66.72 & 1.0 \\
\hline & Betagi & 66.72 & 1.2 \\
\hline & Bibichini & 72.81 & 1.2 \\
\hline & Bura Mazumdar & 55.74 & 1.0 \\
\hline & Hosnabad & 61.86 & 0.91 \\
\hline & Kazirabad & 5.021 & 0.91 \\
\hline & Mokamia & 61.03 & 1.22 \\
\hline & Sarishamuri & 49.55 & 2.13 \\
\hline \multirow[t]{4}{*}{ Bamna } & Bamna & 55.80 & 1.22 \\
\hline & Bukabunia & 56.43 & 1.22 \\
\hline & Dauatala & 46.51 & 1.83 \\
\hline & Ramna & 46.96 & 1.52 \\
\hline \multirow[t]{3}{*}{ Barguna Sadar } & Barguna & 34.84 & 1.83 \\
\hline & Paurashava & 34.84 & 1.83 \\
\hline & Phullhury & 43.26 & 1.80 \\
\hline
\end{tabular}

Source: Field survey, 2008

In addition, field survey data illustrates that there is an inverse relationship between the distance from the coast of the unions and the surge height (Tables 3 and 4; and Figure 5). The reason behind the deviation among surge depth and distance from the coast is due to the number of inlets 
in the Barguna district. The field survey also revealed that the main reason of high flooding was due to embankment failure in the southern part of the district.

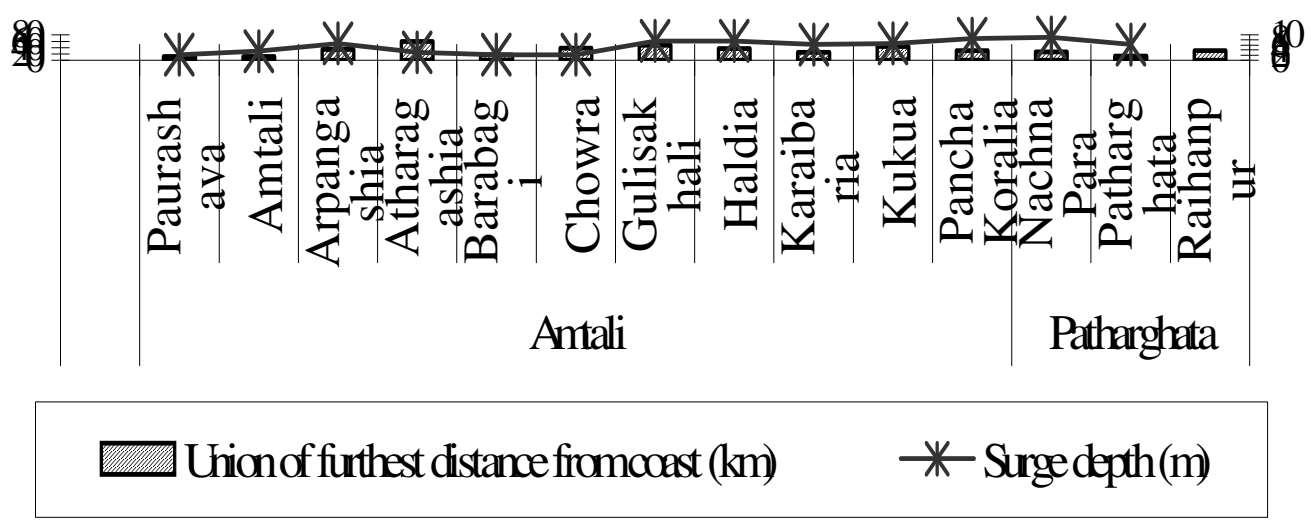

Fig. 5: Comparison with union distance from the coast and their surge height

However, there is a significant difference between the model estimation and the field data. According to the model study, the flood level for cyclone SIDR varies $0.5 \mathrm{~m}-1.0 \mathrm{~m}$. But real scenario demonstrates that the range varies from approximately $1.0 \mathrm{~m}$ to $9.0 \mathrm{~m}$. Moreover the surge level for the predicted cyclone is between $1 \mathrm{~m}$ to above $6.0 \mathrm{~m}$. It may be noted that the field data was collected based on the opinion of local people. There may be some inconsistency between the field data and the prediction of the model study due to some unusual situation in field level scenario such as damage of polder in some points by the local people as a pass way of brackish water from sea to inland for shrimp cultivation. Consequently, the surge level inside the district may be more than the prediction in case of low tide and less wind speed.

\section{Spatial Variation of Socio-Economic Vulnerability}

Substantial spatial variability exists in characteristics used to define socio-economic vulnerability. Based on the category of risk by BUET-BIDS, more than 65 percent of total population and 74 percent of total land area of Barguna district are exposed to risk zone (Table 5). Table 5 depicts that Amtali Upazila is highly vulnerable in which 19.50 percent population of Barguna district are living. Moreover, social vulnerability of Barguna Sadar and Patharghata Upazila is also high (Table 6).

Table 5: Area and population exposure to risk in Barguna district

\begin{tabular}{|c|c|c|c|c|}
\hline Variables & & High Risk zone & Risk zone & Risk free zone \\
\hline \multirow{2}{*}{ Population } & Number & 417599 & 141494 & 289461 \\
\cline { 2 - 5 } & Percentage & 49.21 & 16.67 & 34.11 \\
\hline \multirow{2}{*}{ Area } & Total (Sq. Km) & 940.37 & 212.55 & 354.49 \\
\cline { 2 - 5 } & Percentage & 62.38 & 14.10 & 23.52 \\
\hline
\end{tabular}

Source: Calculated by author, 2009 
Table 6: Union-wise population exposure to risk in Barguna district

\begin{tabular}{|l|l|c|c|c|c|c|c|}
\hline \multirow{2}{*}{ Upazila } & \multicolumn{1}{c|}{ Union } & \multicolumn{2}{c|}{ High Risk area } & \multicolumn{2}{c|}{ Risk zone } & \multicolumn{2}{c|}{ Risk free zone } \\
\cline { 3 - 8 } & & \multicolumn{1}{c}{ No. } & $\%$ & No. & $\%$ & No. & $\%$ \\
\hline Amtali & $\begin{array}{l}\text { Amtali, Arpangashia, Atharagasia, Barabagi, } \\
\text { Chowra, Gulisakhali, Haldia, Karaibaria, } \\
\text { Kukua, Pancha Koralia }\end{array}$ & 165441 & 19.50 & 42774 & 5.04 & 51542 & 6.07 \\
\hline Bamna & Bamna, Bukabania, Dauatala, Ramna & - & - & 16603 & 1.96 & 53200 & 6.27 \\
\hline Barguna Sadar & $\begin{array}{l}\text { Ayla Patakata, Badarkhali, Barguna, Burir } \\
\text { Char, Dhalua, Phuljhury, Gaurichanna, } \\
\text { Keorabunia }\end{array}$ & 144667 & 17.05 & 67256 & 7.93 & 25690 & 3.03 \\
\hline Betagi & $\begin{array}{l}\text { Betagi, Bibichini, Bura Mazumdar, } \\
\text { Hosnabad, Kazirabad, Mokamia, Sarishamuri }\end{array}$ & - & - & 14861 & 1.75 & 104495 & 12.31 \\
\hline Patharghata & $\begin{array}{l}\text { Char Duanti, Kakchira, Kalmegha, } \\
\text { Kanthaltali, Nachna Para, Patharghata, } \\
\text { Raihanpur }\end{array}$ & 162025 & 19.09 & - & - & - & - \\
\hline
\end{tabular}

Source: Calculated by author, 2009

Thus, socio-economic vulnerability of different unions of Barguna district was examined by applying the Population and Structural Index (PSI), Direct Access to Resource Index (DARI), Population Evacuation Need Index (PENI) and Composite Index (CI). The Population and Structural Index (PSI) indicates the vulnerable zones of cyclone disaster in respect of population, house structures (i.e. jhupri, katcha and semi-pucca) and dependence on agricultural activity.

Table 7: Percentage distribution of population, house structure and households in agriculture

\begin{tabular}{|c|c|c|c|c|c|c|c|c|c|c|}
\hline \multirow{2}{*}{$\begin{array}{l}\text { Vulnerability } \\
\text { class }\end{array}$} & \multirow{2}{*}{$\begin{array}{c}\text { Populati } \\
\text { on }\end{array}$} & \multirow[t]{2}{*}{ Percent } & \multicolumn{6}{|c|}{ Structural condition of houses } & \multirow{2}{*}{$\begin{array}{c}\mathrm{HH} \text { in } \\
\text { agricultur } \\
\mathrm{e}\end{array}$} & \multirow[t]{2}{*}{ Percent } \\
\hline & & & Jhupri & Percent & Katcha & Percent & $\begin{array}{l}\text { Semi } \\
\text { Pucca }\end{array}$ & Percent & & \\
\hline Low & 60431 & 7.12 & 2452 & 7.30 & 9881 & 7.11 & 152 & 2.86 & 11431 & 7.90 \\
\hline Medium & 402414 & 47.42 & 16719 & 49.79 & 67372 & 48.48 & 1034 & 19.48 & 71816 & 49.61 \\
\hline High & 84909 & 10.01 & 3501 & 10.43 & 14110 & 10.15 & 216 & 4.08 & 15257 & 10.54 \\
\hline Highest & 65426 & 7.71 & 2044 & 6.09 & 9803 & 7.05 & 1511 & 28.48 & 8557 & 5.91 \\
\hline
\end{tabular}

Source: Calculated by author, 2009

A significant portion (72.26 percent) of population is living within the delineated geo-physical high risk and risk zones indicated as red marks and blue marks respectively. Among them 7.71 percent, 10.01 percent and 47.42 percent population are living in the highest (Barabagi union), high (Patharghata, Kalmegha, Haldia and Gaurichamna unions) and medium vulnerable regions (Baliatali, Pancha Karalia, Char Duanti, Dhalua, Burir Char) in respect of PSI. On the other hand, 6.09 percent, 7.05 percent 28.48 percent of jhupri, katcha and semi-pucca houses respectively are within the highest vulnerable region (Table 7 and Figure 6). 


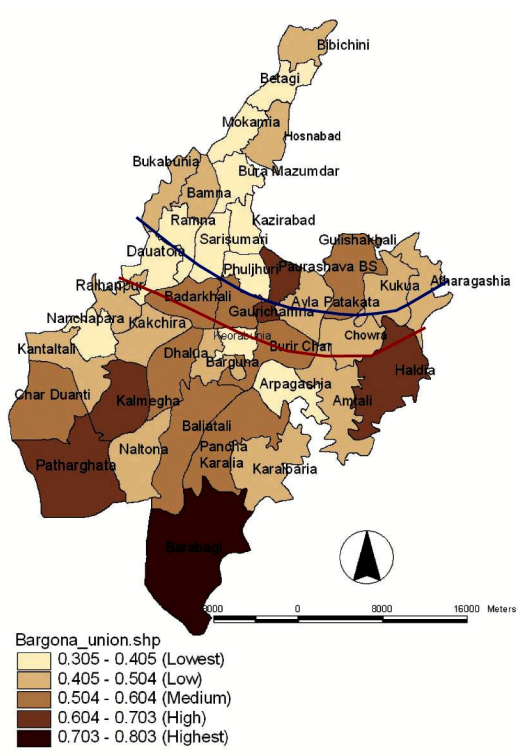

Fig. 6: Social vulnerability based on PSI

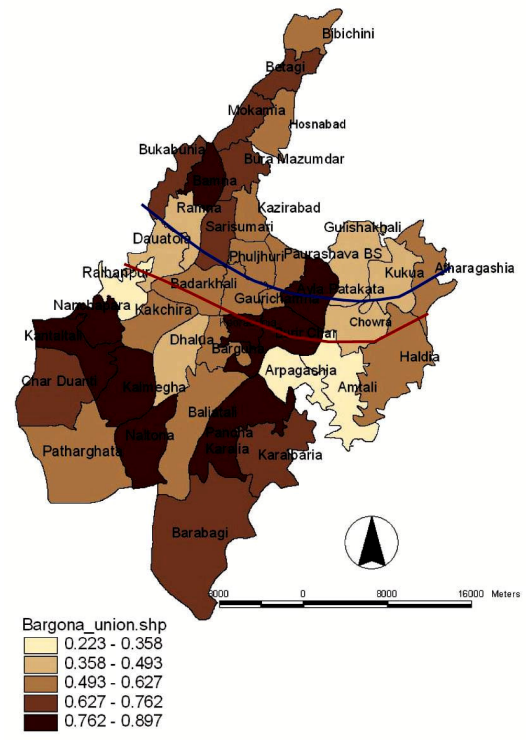

Fig. 7: Social vulnerability based on DARI

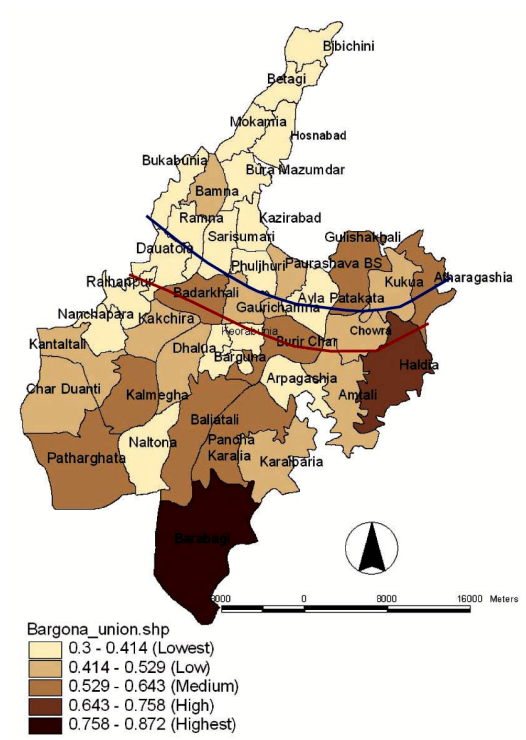

Fig. 8: Social vulnerability based on PENI

Later on, Direct Access to Resource Index (DARI) indicates that Naltona, Kalmegha, Kataltali, Burir Char, Ayla Patakata, Pancha karalia and Bamna unions are the highest vulnerable zone and fall within the geo-physical risk zone (Figure7). Even the provision of basic services and facilities such as safe drinking water, hygienic sanitation, electricity and pucca road are not adequate enough in this zone. About 73.05 percent, 69.74 percent and 95.25 percent households in this zone are deprived of safe drinking water, hygienic sanitation facility and electricity supply respectively. While only $39.34 \mathrm{~km}$ pucca road is available in this zone (BBS, 2006).

Correspondingly, Barabagi and Haldia unions are within the highest and high vulnerable zone respectively based on PENI (Figure 8). While Patharghata, Baliatali, Pancha Karalia, Kalmegha, Burir Char, Barguna and Badarkhali unions falls in the medium vulnerable zone (Figure 8).

About 5.09 percent, 4.21 percent and 4.62 percent people of age less than 5 years, age greater than 60 years and disabled respectively are categorized as the highest vulnerable groups. While 3.47 percent, 3.66 percent and 3.67 percent of age less than 5 years, age greater than 60 years and disabled people respectively are categorized as high vulnerable (Table 8).

Table 8: Percentage distribution of people need evacuation assistance

\begin{tabular}{|l|c|c|c|c|c|c|}
\hline \multicolumn{1}{|c|}{ Vulnerable class } & Age $<5$ years & Percent & Age 60+ years & Percent & Disabled & Percent \\
\hline Lowest & 19200 & 18.79 & 13192 & 19.10 & 10630.272 & 19.94 \\
\hline Low & 15281 & 14.96 & 10489 & 15.19 & 8611.008 & 16.15 \\
\hline Medium & 27401 & 26.82 & 18352 & 26.57 & 14596.544 & 27.38 \\
\hline High & 3543 & 3.47 & 2526 & 3.66 & 1954.88 & 3.67 \\
\hline Highest & 5198 & 5.09 & 2907 & 4.21 & 2462.208 & 4.62 \\
\hline
\end{tabular}

Source: Calculated by author, 2009 
Later on, Composite Index of socio-economic vulnerability was determined based on the weighted overlay of three indices. Composite Index indicates that within the geo-physical risk zone Barabagi union is the highest socio-economic vulnerable area, while Pancha Karalia, Baliatali, Patharghata, Char Duanti, Kalmegha, Haldia and Burir Char are in high vulnerable zone. On the other hand, Naltona, Karaibaria, Dhalua, Kanthaltali, Badarkhali, Gaurichamna, Nachnapara, Ayla Patakata, Artharagasia and Keorabunia unions are within the medium vulnerable zone (Figure 9).

\section{Quantitative Comparison of Results}

Although the four maps (Figure 6-9) provide a visual assessment of evacuation assistance need patterns within the study area, the analytical capabilities of GIS software can be used to estimate the total population in each evacuation assistance need zone, as well as their socio-economic and structural characteristics.

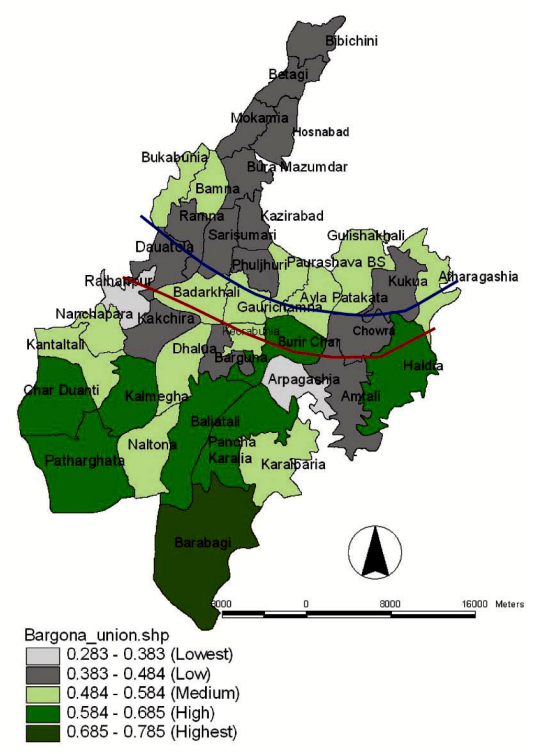

Fig. 9: Social vulnerability based on Composite Index (CI=PSIxDARIxPENI).

These numerical estimations interpret the variability of results obtained from the four different approaches to measure social vulnerability in conjunction with geophysical risk. Four approaches are compared quantitatively by focusing on two specific aspects that are important for risk management and evacuation planning: (1) the number of people living in each evacuation assistance need zone; and (2) the characteristics of the population and structures in areas with the highest evacuation assistance need.

Table 9: Percent of Population within Evacuation Assistance Need Zones

\begin{tabular}{|l|c|c|c|c|}
\hline Evacuation needs & Approach 1 (\%) & Approach 2 (\%) & Approach 3 (\%) & Approach 4 (\%) \\
\hline Lowest & 8.39 & 6.34 & 15.41 & 3.54 \\
\hline Low & 7.12 & 4.74 & 18.15 & 14.41 \\
\hline Medium & 47.42 & 22.99 & 18.46 & 22.15 \\
\hline High & 10.01 & 9.78 & 3.60 & 22.28 \\
\hline Highest & 7.71 & 17.82 & 8.53 & 8.53 \\
\hline
\end{tabular}

Source: Calculated by author, 2009 
Approach 1 indicates that almost 17 percent of the district population can be found in areas where evacuation assistance need is high or the highest; this figure is about 27 percent for Approach 2, about 11 percent for Approach 3 and 31 percent for Approach 4. The numerical differences among the estimates obtained from the four approaches are reasonably consistent with the variation in patterns observed in our visual assessment of the four maps except in case of Approach 4. The result in Approach 4 indicated that 17.82 percent of the total population in Barguna district suffers from the scarcity of resource. This may create post disaster problem like epidemics because of lack of availability in water supply, sanitation and other available and basic necessities. Moreover, due to lack of electricity and road network, the relief material works would be delayed.

\section{Conclusion}

The social and geophysical vulnerability maps and quantitative analyses provide an empirical basis upon which the objectives of the study can be addressed. First, the coastal unions of Barguna district are identified as geophysical risk zone such as Raihanpur, Bardarkhali, Keorabunia, Burir Char, Amtali, Haldia, Arpagashia, Barguna, Dhalua, Kakchira, Nachnapara, Kantaltali, Char Duanti, Kalmegha, Patharghata, Barabagi, Karaibaria, Pancha Karalia, Naltona, and Baliatali unions are within the high geophysical risk zone. On the other hand, socio-economic vulnerability is the highest in Barabagi union. In fact, majority of the unions are characterized by high evacuation assistance need. Because it is known that those population, who live in socioeconomically vulnerable area are at risk and many are living in high geophysical risk region. In the quantitative analysis, similar scenario exists in the spatial distribution of geophysical risk and vulnerability i.e. those unions, which are in high risk zone, are socio-economically vulnerable and those who are less geo-physically risky are less socio-economically vulnerable such as Bibichini, Betagi, Mokamia, Hosnabad, and Buro Mazumdar unions. Nevertheless, spatial disparity of socioeconomic vulnerability was observed among the unions within the geophysical risk zone, such as Raihanpur and Arpagashia unions are lowly socio-economic vulnerable region but fall within the high geophysical risk zone. The results also indicate the important fact that the variables used for vulnerability analysis make a difference. Depending on which the measures used, 72.26 percent people are living in the geophysical risk zone, while 17.72 percent and 47.42 percent people are living in the high and medium socio-economic vulnerable regions respectively. Thus 65.14 percent people require evacuation assistance need.

The results of the socio-economic vulnerability analysis have important implications for emergency management and especially for evacuation planning. However, because of the scarcity of resources, special needs for evacuation assistance in the form of early warning, mobility assistance, or both should be given the highest priority in those areas which are highly socioeconomically vulnerable and geophysically risky. For example, Barabagi, Patharghata, Baliatali, Haldia, Pancha Karalia and Kalmegha unions require the highest priority.

In recapitulation, it can be said that the results of this research demonstrate the importance of evaluating both risk and vulnerability from several perspectives of emergency management purposes. However, much more considerations to be made if we are to develop dynamic, effective, and efficient evacuation plans. For example, the location and capacity of evacuation routes will greatly influence the success (or lack of success) of any evacuation process. Within the spatial analysis, transportation networks can be incorporated in order to identify optimal evacuation routes.

\section{References}

Bangladesh Bureau of Statistics (BBS), 2006. Community Series 2001, Dhaka: Planning Division, Ministry of Planning, Government of the People's Republic of Bangladesh.

Bangladesh University of Engineering and Technology and Bangladesh Institute of Development Studies, 1993. Multipurpose Cyclone Shelter Programme, Final Report, Dhaka: Planning Commission, UNDP, and World Bank. 
Banglapedia, 2006. National Encyclopedia of Bangladesh, CD edition, Dhaka: Asiatic Society of Bangladesh.

Blaikie. P., Cannon, T., Davis, I., Winser, B. 1994. At risk: Natural hazards, people's vulnerability, and disasters, London: Routledge.

Chakraborty, J., Tobin, G. A., and Montz, B. E. 2005. 'Population Evacuation: Assessing Spatial Variability in Geophysical Risk and Social Vulnerability to Natural Hazards', Natural Hazards Review, ASCE, February, pp. 23-33.

Clark, G. E., Moser, S. C., Ratick, S. J., Dow, K., Meyer, W. B., Emani, S., Jin, W., Kasperson, J. X., Kasperson, R. E., and Schwarz, H. E. 1998. 'Assessing the vulnerability of coastal communities to Extreme storms: the case of revere, MA. USA' Mitigation and Adaptation Strategies for Global change, vol. 3, pp.59-82.

Cutter (ed.) 2001. American Hazardscapes: The Regionalization of Hazards and Disasters. Washington, D.C.: Joseph Henry Press.

Cutter, S. L 1996. 'Vulnerability to environmental hazards', Progress in Human Geography, vol. 20(4), pp.529-539.

Dow, K. 1992. 'Exploring differences in our common future(s): The meaning of vulnerability to global environmental change', Geoforum, vol. 23(3), pp. 417-443.

Hewitt, K. 1997. Regions of risk: A Geographical Introduction to Disasters, Singapore: Longman.

Islam, T. 2008. Cyclone Wind Analysis and Disaster Planning- An Integrated Approach for the Bangladesh Coast. Germany: VDM Verlag Dr. Muller.

Kasperson, J. X., Kasperson, R. E and Turner, B. L., (eds.), 1995. Regions at risk: Comparison of Threatened Environments, Tokyo: United Nation University Press.

Maniruzzaman, K. M. 1997. GIS-based Disaster Management System for Cyclone Disaster Response in Bangladesh, PhD thesis, Department of Urban Engineering, School of Engineering, University of Tokyo.

Montz, B. E. 1994. 'Methodologies for analysis of multiple hazard probabilities: An application in Rotorua, New Zealand', Falbright Research Scholar Report, Centre for Environment and Resource Studies, University of Waikato, Hamilton, New Zealand.

Network for Information, Response and Preparedness Activities on Disaster 2007. Cyclone SIDR kills hundreds in Barisal and Khulna Division. http:/www.nirapad.org retrieved on $15^{\text {th }}$ July 2008.

Susman, P., O' Keefe, P., and Wionser. B. 1983. 'Global disasters and radical interpretation' K. Hewitt. (ed.) Interpretation of calamity, Boston: Allen and Unwin.

Tobin, G. A., and Montz. B. E. 1997. Natural hazards: Explanation and integration, New York: Guiford Press.

United Nations International Strategy for Disaster Reduction, 2001. Targeting vulnerability: Guidelines for local activities and events, Geneva: UNISDR, Switzerland.

Water Resource Planning Organization, 2004. Where land meets the sea-a profile of the coastal zone of Bangladesh, Dhaka: University Press Limited. 